\title{
Dynamic Tests of a Leg in a Powered Roof Support Equipped with an Innovative Hydraulic System
}

\author{
Dawid Szurgacz ${ }^{1, *}$, Jarosław Brodny ${ }^{2}$ \\ ${ }^{1}$ Center of Hydraulics DOH Ltd, ul. Konstytucji 147, 41-906 Bytom, Poland \\ ${ }^{2}$ Silesian University of Technology, Faculty of Organization and Management, Roosevelta 26, 41-800 \\ Zabrze, Poland
}

\begin{abstract}
Static and dynamic loads impact on a powered roof support during its operation. The dynamic loads lead to a number of consequences for the construction and the entire hydraulic system. With the increase of depth and intensity of exploitation, the number of events during which the dynamic load is greater increases. Therefore, it is necessary to research the whole unit of the support and its components under the impact of dynamic load. The article presents the results of tests of a hydraulic leg designed to work in the powered support and dynamically loaded with free fall drop. An innovative hydraulic system type DOH was mounted in the subject leg. As a result of the conducted tests, the dynamic parameters of the tested system were determined. The aim of the research was also to determine the impact of drop's energy on the operating parameters of the tested system. The tested hydraulic system is a part of an innovative electro hydraulic control system of the powered roof support. The Authors believe that the obtained results will allow to create opportunities for the practical application of the tested system and the entire wireless control system of the mining roof support.
\end{abstract}

\section{Introduction}

Hard coal is a widely used energy resource. It is the basic fuel on which the entire economy is based in many countries. Global forecasts clearly indicate that for the next decades coal will remain one of the basic energy raw materials in the world. However, similarly to other raw materials, the coal market is also subject to the laws of a market economy. As a result, mining enterprises dealing with its exploitation must to an even greater extent care for the effectiveness and safety of the mining exploitation process. In this respect, the use of innovative solutions in the field of work organization and technical equipment is crucial. The aim of these activities is to improve the operational safety and reduce unit costs of the product. In Poland, as in Russia, more and more attention is devoted to the development of innovative systems supporting these processes. In both countries, coal is a very important raw material that has a significant impact on the entire economy. Cheap energy is the key

* Corresponding author: dawidszurgacz@doh.com.pl 
factor determining the competitiveness of any economy. In both countries, a number of tests and analyses are carried out to optimize the coal exploitation process. Such activities include almost every area related to mining operation. One of the most interesting areas deciding about the level of safety, and later on the efficiency of the exploitation process, is the mine technical equipment and its optimal use [4, 9,]. In this respect, the most important areas include mining machines which are the components of the powered support unit. The task of such unit is to ensure the continuity of the mining process. In the entire technological process of hard coal production, the most significant is the area associated with mining and transport from the longwall zone.

This is due to the fact that currently, as the intensity and efficiency of the process is high, exploitation is carried out by longwall systems. They ensure high concentration of extraction and the possibility of complete mechanization of the process. To achieve operational efficiency, it is necessary to select appropriate machine. It must be easy to use, with high technical parameters and a high degree of reliability. Safety of use is also significant. Such machine must be very crew-friendly so that it does not pose an additional threat to the operators and miners. It should be remembered that the underground exploitation process is carried out in a very difficult environment, in which there are a number of natural hazards, including rock bursts and ventilation hazards [2,3]. Posing even more threats such as technical or organizational ones would additionally complicate and hinder the mining process, therefore, it is necessary to conduct all types of work to develop innovative solutions that would facilitate the work of the crew, improve safety and increase the level of efficiency.

Required level of safety of the mining unit is provided by the powered roof support. Its task is to protect the work are of the crew, enable monitoring and control of the operation process and cooperation with a longwall conveyor and shearer. The support is a combination of mechanical and hydraulic elements based on control systems. Conducting work in the field of optimizing the work of the roof support seems reasonable, as with the increasing efficiency and high concentration of extraction, it is the roof support that must provide proper working conditions. The basic part of the powered roof support is the section of the support.

The section of the powered roof support in the longwall complex is responsible for a set of functions. Most of these functions are carried out using hydraulic cylinders. Each hydraulic cylinder is controlled by the associated control system. The hydraulic cylinder along with the distributor and power source controlling it form a basic hydraulic system. Such system is of crucial importance. All functions and activities performed by the section are dependent on the efficiency, quality and efficiency of the hydraulic system. Therefore, the presented article focuses on the study of the hydraulic system of the powered roof support section. The basic element of this system are hydraulic legs. Their operation determines the working parameters of the entire support in terms of securing a longwall area. They determine the level of support. The system in which these actuators work consists of an additional valve block and safety valves. Proper operation and condition of safety valves are extremely important for the whole system. Their task is to protect against overload the under-piston space and/or over-piston of the hydraulic leg.

Due to the fundamental importance of hydraulic leg in terms of operation of the roof support, the Authors of the research focused on tests of these elements. Hydraulic legs are impacted by loads generated by rock mass which may lead to destruction of the unit. The impact is static or dynamic. It was assumed that dynamic phenomena lead to greater number of consequences. Therefore, it was decided to perform tests on hydraulic legs under dynamic loading. The energy of a free-fall drop was used as the source of the load. It has been assumed that the impact load in a very similar way reflects the dynamics of the support load in real conditions. 
The goal of the research was to determine the parameters of the leg under dynamic load. At the same time, the research time decided to apply the innovative mobile DOH1 data registration system. The system developed by the Authors enables very precise registration of work parameters of the leg as well as the entire support. The system uses original sensors to measure pressure and an innovative system of registration, archiving and processing of data obtained. New designs of safety valves were also included in the tests. In particular, attention was paid to the reaction speed of these valves, their overload and the opening time. Such parameters are significant and, in many cases, may decide about the safety of the area where miners work. At the same time, the work of the entire hydraulic system must ensure a continuous work and adequate speed of operation. Properly operating powered roof support must keep its stability when the legs are slid down as well as when they are slid out between the roof and the floor. To achieve this, the hydraulic system must be properly selected and effective.

The results presented in the article are only a part of the extensive research material that has been obtained in the results of conducted tests and analysis. It mainly concerns the study of a new measurement system and determination of the impact of drop energy on the hydraulic leg work parameters.

\section{Methodology and Scope of Research}

The bench test of the hydraulic leg together with the entire hydraulic system was carried out in a drop-weight testing station provided by the TLO Laboratory in Opava. The research included a double-telescopic hydraulic leg with a $\varnothing 250 \mathrm{~mm}$ diameter created by Hydrotech. The tested leg together with the hydraulic equipment is presented in Figure 1.

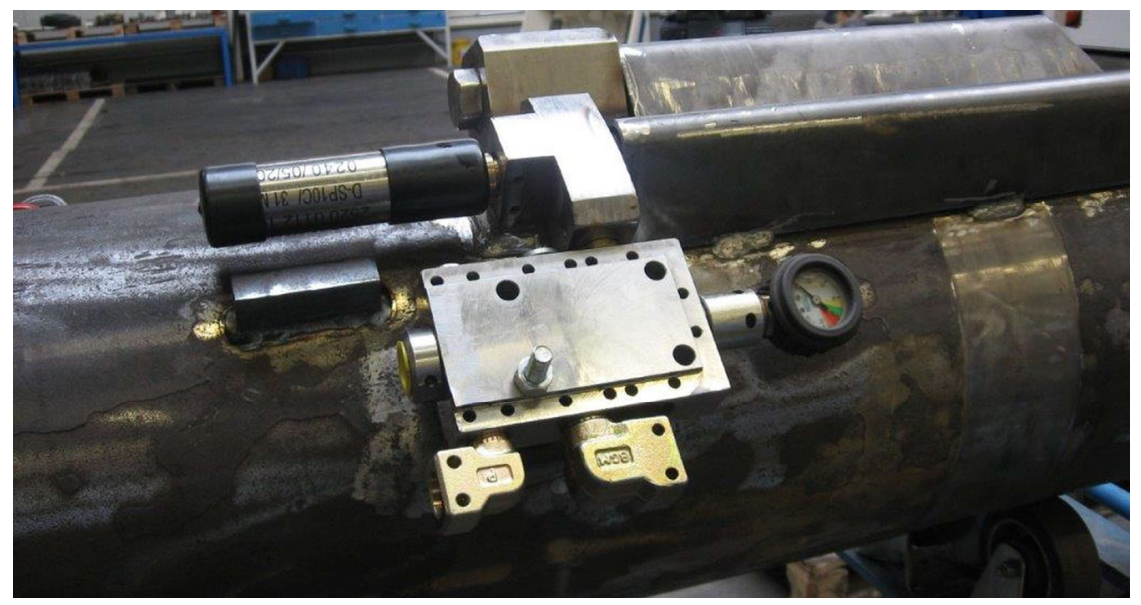

Fig. 1. The Hydrotech hydraulic leg prepared for testing with a diameter of Ø250 MM equipped with a DOH hydraulic system.

During the tests, the leg was subjected to a dynamic free-fall drop. The pressure of the liquid in the under-piston space of the leg and the valve block were measured during the tests. The test results were recorded by the innovative DOH12SzBr system. This system comprises a control and intermediary module that allows testing of the operation of individual control elements of the powered roof support. It was developed using the National Instruments cRIO9030 card. This module is equipped with two different operator interface devices. Communication with the system is based on an Ethernet link and a PC which is equipped with software created in the Lab View environment. 
Figure 2 presents the view of the test bench together with the mounted leg and individual elements of the hydraulic system of the leg. These elements have been appropriately marked as presented below in Figure 2. Such system was subjected to dynamic testing based on a free-fall drop.

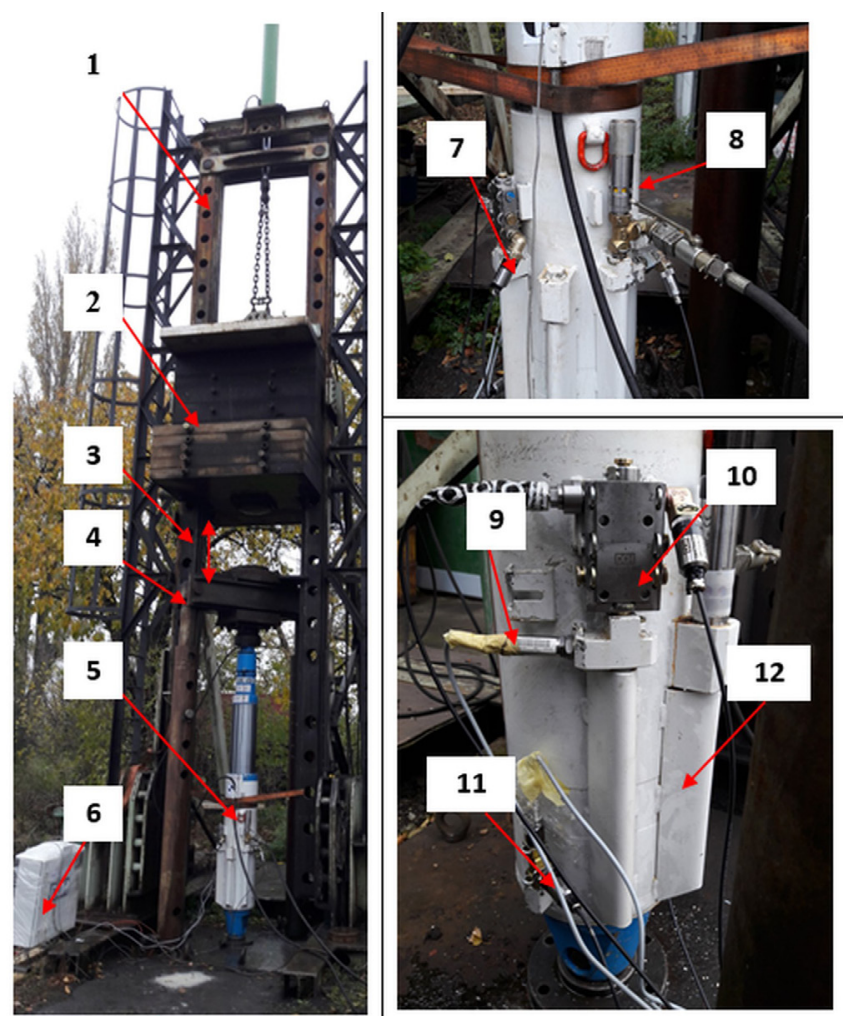

Fig. 2. The test bench and the elements of the hydraulic system: 1 - impact guiding gear, 2 -impact weight $20,000 \mathrm{~kg}, 3$ - drop height, 4 - crossbar locking pin in the frame, 5 - hydraulic ram piston rod, 6 - innovative measuring system, 7 - valve block with pressure sensor, 8 - tested safety valve, 9 sensor placed in the pressure supply connection, 10 - valve block fixed in the connection, $11-$ pressure sensor located in the under-piston space of the leg, 12 - connection for discharge of liquid from the space under the piston of the leg to the valve.

The test was based on an axial loading with a dynamic impulse (drop-weight) of the hydraulic leg. A safety valve and valve block were connected to the space under the piston of the leg. A pressure sensor was located in the connection that connects the safety valve with the under-piston space of the leg. The pressure sensor was connected to the space under the piston of the leg and the valve block. Sensors was connected to an innovative recording and measuring system. The tests were conducted for a leg with an extended piston with a height of $\mathrm{h}=2.6 \mathrm{~m}$. These dimensions were maintained during all tests. The length of the stand extension has a significant impact on the results obtained. The tests adopted the value of this parameter due to the fact that in practice such a length occurs most often.

Prior to the test the leg was attached in the correct position and initial load-bearing capacity was set. Impact weight of $20,000 \mathrm{~kg}$ was dropped from a height of $0.1 \mathrm{~m}$ to $0.7 \mathrm{~m}$ measured from the upper surface of the leg. Three tests were conducted for each value of the height from which the impact weight dropped.

Impact mass energy was determined from the following dependence (1). 


$$
E_{u}=m v^{2} / 2=m g h
$$

where:

$g$ - gravitational acceleration equal $9.81 \mathrm{~m} / \mathrm{s}^{2}$,

$m$ - mass of the drop,

$\mathrm{v}$ - speed with which the drop hits the leg, (calculated from $\mathrm{v}=\sqrt{ } 2 \mathrm{gh}$ )

This dependence determines the kinetic energy, equal in this case to the potential energy, and referred to as the energy of the impact of the freely falling weight $(m)$ from a set height (h).

The sensors were located in the space under the of leg's cylinder and in the valve block connected with DN 12 DN 19 connections.

\section{Results and discussions}

As a result of drop mass $(m)$ impacting on the hydraulic leg, the kinetic energy of the mass was transmitted by the drop weight to the tested hydraulic system of the leg. A significant part of this energy moves the piston in the leg. This occurs when the safety valve of the leg is opened. The rest is dispersed in the hydraulic and mechanical system. If the safety valve did not open, the whole energy was supplied by hydraulic and mechanical systems. The component which was dispersed in the test stand (vibrations and deformation of the station's elements) should also be included in this energy balance.

After the impact, the drop weight's movement is stopped, which is synonymous with the loss of kinetic energy by the drop weight. Immediately after that, the elastic energy of the leg's cylinder and liquid lifts the drop weight. The whole process can be repeated several times until all the energy of the impact is dispersed. Impact weight loading the hydraulic leg causes an increase in pressure in its under-piston space. In contrast, the upward movement results in relief and pressure drop in this space.

The dependencies determining the time pressure changes in the space under the piston of the hydraulic leg determine the operating characteristics of the leg at a given impact energy. Such characteristics, for a drop in impact weights from 0.4 and $0.7 \mathrm{~m}$, are presented in Figures 3 and 4.

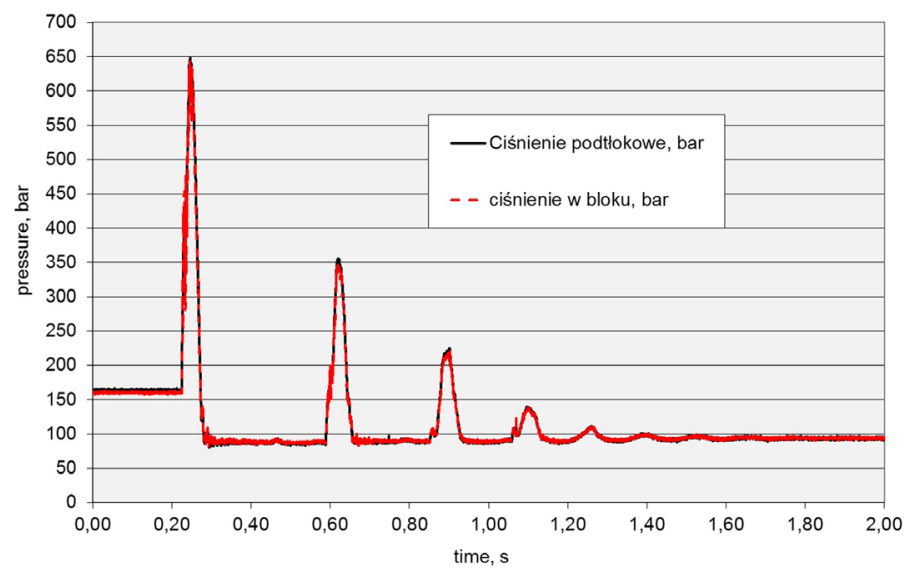

Fig. 3. Performance characteristics of a hydraulic leg loaded with a free-falling impact mass from a height of $0.4 \mathrm{~m}$. 


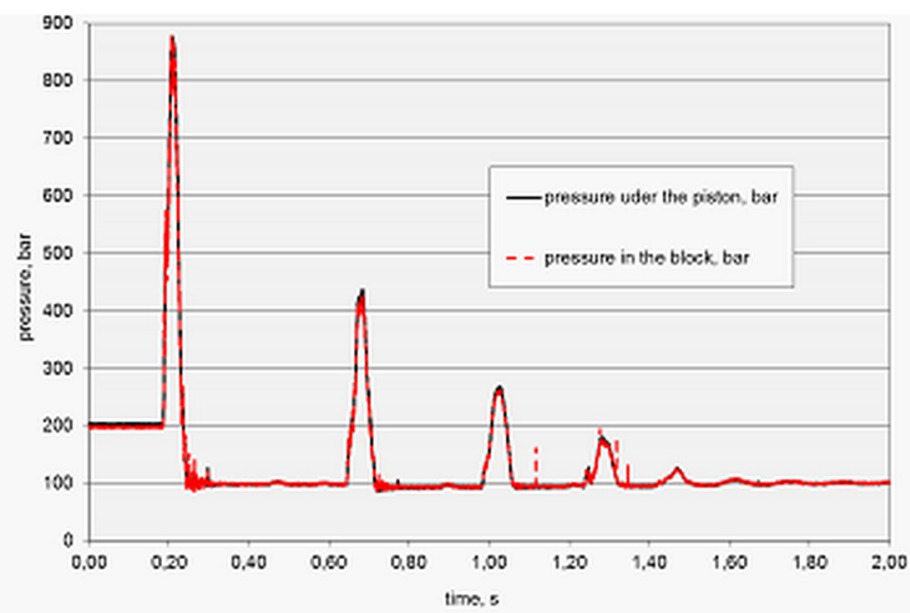

Fig. 4. Performance characteristics of a hydraulic leg loaded with a free-falling impact mass from a height of $0.7 \mathrm{~m}$.

The presented waveforms also show the pressure change in the valve block of the leg. The obtained results present that depending on the energy of the impact, different pressure values were registered in the system. The obtained results allowed to determine the dependence of the impact energy on the maximum pressure value registered in the space under the piston and in the valve block of the tested leg (Figure 5).

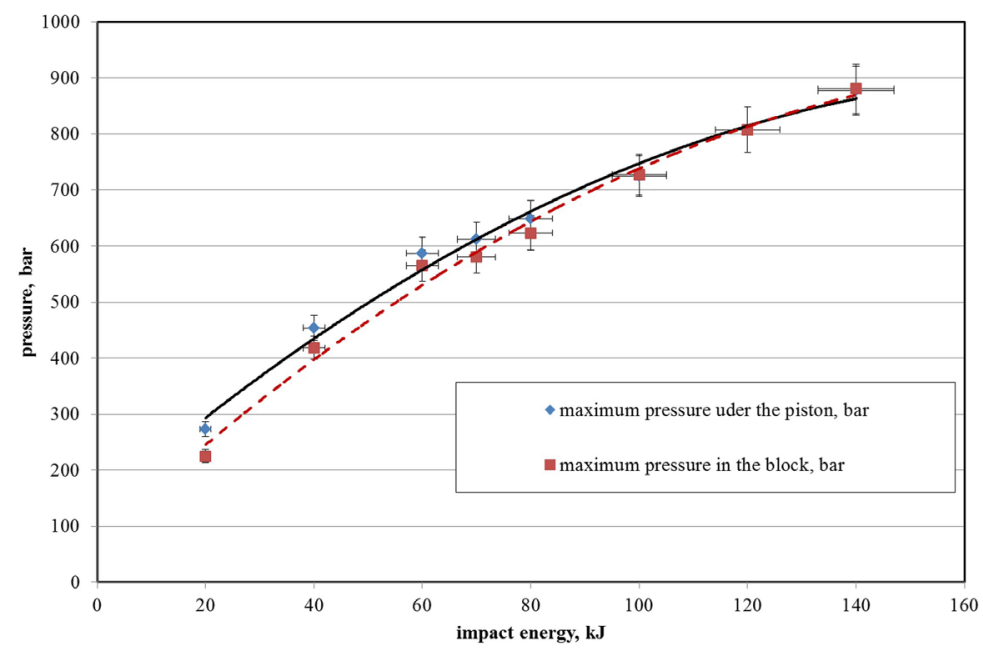

Fig. 5. The dependence of the impact energy and the maximum pressure recorded in the leg's space under the piston.

Analysing the obtained results, it can be concluded that an increase in the value of the impact energy causes an increase in the pressure at which the safety valve in the hydraulic leg is opened. The presented research included the results for the new design of the safety valve. It is clearly visible that its operation, despite the large range of changes in drop energy, is relatively stable. 


\section{Conclusions}

The research and the results obtained unambiguously indicate the validity of the adopted methodology. Similar phenomena have been observed during operation in an active mine. Registered parameters of the leg clearly describe its behaviour in case of dynamic load. The obtained results also indicate the significance of the safety valve mounted in the hydraulic leg. This is confirmed by the analysis comparing the pressure values in the space under the piston and on the valve block. Lack of this valve or its failure may lead to a dynamic and high pressure increase, which may cause damage to the leg. The safety valve included in the tests fulfilled its task. For various values of impact energy, the pressure at which it opened was relatively stable. It proves its stability and good operating parameters.

The innovation system included in the tests fulfilled its role. The whole cycle of tests proceeded without any disturbances, and the recorded waveforms show high stability of the system.

As it was mentioned before, the presented results are only part of the material that was recorded during the research. The results indicate that the developed systems operated correctly in practice. This creates a great opportunity to develop an innovative system without need to apply wired control of the powered roof support. It seems that the valve used and the entire control system included in the tests can be successfully applied in the new system. The authors believe that the obtained results and the developed systems will significantly improve the work safety and maintenance of the powered roof support, and thus also affect the improvement of the economic efficiency of mining enterprises.

The work was carried out within the project 'Innovative electrohydraulic control system for powered roof support'. POIR.01.01.01-00-1129/15. Intelligent Development Operational Programme 2014-2020 carried out by the National Centre for Research and Development.

\section{References}

1. M. Blaschuk, A. Dronov, A. Koperchuk, R. Chernukhin, V. Litvienko, E3S Web of Conferences, The $1^{\text {st }}$ International Innovative Mining Symposium, 15, 03003 (2017)

2. J. Brodny, M. Tutak, SGEM Conference Proceedings, 2, 299 (2016)

3. J. Brodny, M. Tutak, SGEM Conference Proceedings, 2, 897, (2016)

4. J. Brodny, M. Tutak, E3S Web Conferences, 29, 2267 (2018)

5. G. Buyalich, K. Buyalich, M Byakov, E3S Web of Conferences, 21, 03018, (2017)

6. Dokumentacja Techniczno - Ruchowa zaworu SP14 (DOH-DAGOS, 2017)

7. S. V. Klishin, V.I. Klishin, G. Yu. Opruk, Jorunal of Mining Science, 49(6), 932 (2013)

8. S. Prusek, S. Rajwa, A. Wrana, A. Krzemień, International Journal of Mining, Reclamation and Environment, 31(8) (2017)

9. Sprawozdanie z badań $n r$ 35000267-180, (2017)

10. K. Stecuła, M.Tutak, J. Brodny, 17th International Multidisciplinary Scientific Geoconference SGEM, 17(13) 93 (2017)

11. D. Szurgacz, E3S Web of Conferences, 29, 00006 (2018)

12. D. Szurgacz, J. Brodny, E3S Web of Conferences, 29, 00007 (2018)

13. M. Tutak, J. Brodny: IOP Conf. Series: Earth and Environmental Science, 95 (2017) 